\title{
Fabrication of a Porous Ceramic Material Suitable for Cost-effective Thermal Insulation of Buildings
}

\author{
Odewole Peter Oluwagbenga \\ Federal University of Technology, Akure, 340252, Nigeria \\ E-mail: peterodewole@gmail.com \\ Folorunso Davies Oladayo \\ Federal University of Technology, Akure, 340252, Nigeria
}

Received: 11 May 2020; Accepted: 25 July 2020; Published: 08 October 2020

\begin{abstract}
The domestication of cost-effective, green, and sustainable building materials is significant towards its massive adoption in the developing countries. The feasibility of developing porous ceramics for cost-effective thermal insulation of buildings was explored in this study using waste materials including granite shifting and sawdust as well as chemical reagents including water glass and sodium hydroxide. Granite shifting and sawdust were dried, processed into powdered form, milled and sieved. Samples of porous ceramics were formulated using varying percentages by weight of granite shifting and sawdust mixed with a constant percentage by weight of water glass and sodium hydroxide in three different cases. The homogenized powder of the formulated composition was uniaxially pressed at 10Mpa. The samples were dried and then sintered in a gas kiln at 8500C for 3 hours. The result revealed water absorption (21.1-56.5\%), compressive strength (1.2-7.9Mpa), bulk density $(1.44-1.81 \mathrm{~g} / \mathrm{cm} 3)$, apparent porosity $(38.1-81.3 \%)$, and thermal conductivity $(0.13-0.54 \mathrm{~W} / \mathrm{m} . \mathrm{K})$. These results indicated that the obtained porous ceramics is a potential material for cost-effective thermal insulation of buildings where a suitable combination of thermal conductivity, porosity, and mechanical strength is required.
\end{abstract}

Index Terms: Thermal Insulation, Porous Ceramics, Cost-effective Fabrication Technique, Waste Upcycling, Green and Sustainable Building Materials

\section{Introduction}

The primary purpose of a building is not only to provide shelter but also thermal comfort to the occupants. Many alternative efforts that are used to restore thermal comfort when absent in buildings often result into huge energy consumption and carbon emission. Given this, buildings account for a significant percentage of world's energy consumption and also contribute enormously to global carbon emissions. Buildings are responsible for more than $40 \%$ of the world's total primary energy consumption as well as over 33\% of annual carbon dioxide emissions [1]. Greenhouse gas emissions arising from energy consumption in buildings significantly exceeds those from transportation and industrial activities; and carbon emission from fossil fuels as well as electricity use in buildings is expected to increase from 8.6 billion tonnes in 2004 to 15.6 billion tonnes in 2030 under a high growth scenario [2]. Also, heating and cooling demands in buildings are responsible for the highest energy consumption percentage (more than 60\%), followed by lighting which accounts for 11 to $20 \%$ energy demand [3].

Given the global concern to reduce carbon emission and energy bills, thermal insulation is an important technology to reduce energy consumption in buildings by preventing heat gain and loss through the building envelope and at the same time reducing carbon emission which results from cooling buildings using mechanical and electrical driven devices such as air-conditioners and fans. Not only does thermal insulation reduce heat dispersion, it also optimizes the performance of buildings throughout the seasons, thereby making homes warmer in cold season and keeping them cooler in hot season. The use of thermal insulation materials in buildings is of chief importance in present times than ever before due to the effect of climate change that is exposing all the nations of the world to extreme hot and cold weather. For instance, in Nigeria, extreme heat wave in which the temperatures escalated to about 42.20C in certain parts of the country sometimes in April 2019 was reported by Nigerian Meteorological Agency [4]. Also, a recent weather report by the National Centre for Remote Sensing (NCRS) on 3rd January, 2020 stated that the temperature of Jos dropped to as low as 6.70C [5].

However, despite that porous ceramics is a promising material that offers eco-friendliness and sustainability in terms of waste remediation and thermal insulation of buildings, available information and research on porous ceramics for 
thermal insulation is still scarce in developing countries such as Nigeria. Based on professionals' perspectives, nonavailability of local green building materials has been identified as one of the major hindrances to green building developments in Nigeria's built environment [6]. It thus becomes imperative to channel more research efforts towards domestication of cost-effective green building materials in the country. Given that cost is one of the major deterring factors to the massive adoption of thermal insulation of buildings in Nigeria, the possibilities of developing cost-effective wall insulation materials using indigenous ceramic technology in Nigeria have been extensively discussed in a previous study [7]. As the global insulation market is expected to reach approximately US $\$ 65.0$ billion by 2020, growing at a compound annual growth rate of about 8.0\% between 2015 and 2020 [8], promoting community level job creation and incomegenerating activities through the development of insulation materials such as porous glass-ceramics in Nigeria is necessary. To this end, the viability of porous ceramics production for cost-effective thermal insulation of buildings was explored in this study using waste materials such as granite shifting and sawdust.

Even though in the past, the presence of porosity in ceramics had always been considered a problem and significant scientific efforts were made to devise processing routes to manufacture materials with zero porosity, nowadays cellular structure materials such as foamed, reticulated and biomorphic ceramics are attractive for their numerous technological applications [9]. Porous ceramics have found applications in sound insulation, thermal insulation and also as lightweight aggregates concrete used in building and construction [10]. Different techniques have been used in the fabrication of porous ceramics which include but not limited to foaming by gas dissolution, foaming by microwave heating, foaming by hydrothermal process and foaming by sintering [11]. Among all these, sintering method has been widely and commonly used due to the fact that it offers easy usability with optimum results [12]. There are two-step and single-step sintering methods of porous ceramics fabrication. However, combining the typical two steps operation into a single operation when raw materials are mixed and heat treated with formation of the foamed or porous material is more economically acceptable [13]. This implies that single-step sintering technology of porous ceramics is a cost-effective fabrication technique.

While single-step sintering technology have been mostly used with industrial wastes such as waste glass, fly ash and metallurgical slag, the possibility of single-step sintering technology of porous ceramics from naturally sourced materials has also been experimented considerably. [14] investigated into the possibility of single-step sintering technology of porous glass-ceramic production by using tripoli and microsilica with the addition of microsilica as a minor constituent in the batch in the amount of 10 to $50 \mathrm{wt} . \%$ and $45 \%$ sodium hydroxide solution as an alkaline component at foaming temperatures of $830-850^{\circ} \mathrm{C}$. [13] studied into foam glass-ceramics production using diatomite as a base raw material. A mixture of diatomite and $40 \% \mathrm{NaOH}$ solution was subjected to heating at a constant temperature of $775^{\circ} \mathrm{C}$. Samples of foam glass-ceramic from diatomite with an average density of $290-580 \mathrm{~kg} / \mathrm{m} 3$, compressive strength of $1.7-7.8 \mathrm{MPa}$ and thermal conductivity of $0.08-0.14 \mathrm{~W} / \mathrm{m} . \mathrm{K}$ were obtained. [15] experimented into chemical technology of cellular glass production using $\mathrm{NaOH}$ solution (varied from 6-12\%). Given that two-step sintering is considered more energy consuming, this study, therefore, investigated into the development of porous ceramics from granite shifting and sawdust using single-step sintering technology.

Reducing the impact on the environment is therefore a major concern to granite industries in Nigeria [16], [17] since accumulation of granite shifting as a quarry waste can pollute soil and rivers [18]. However, there are much potential in granite shifting that are still untapped in the country despite the fact that it can be used as a raw material for many manufacturing processes. Findings have shown its suitability for ceramic processing [19, 20], glass and glass-ceramics production [21], as well as foam glass production [22]. It is also noteworthy that organic wastes such as sawdust are composed of important elements which open many value-adding opportunities and can be a low-cost alternative for use as pore-forming agents [23]. The use of pore forming agents in the development of porous ceramic materials is purposely to increase the thermal insulating property of wall systems, thereby resulting into the reduction of heat energy consumption in the buildings [24]. Sawdust has been found to mainly consist of carbon, hydrogen, oxygen and nitrogen [25] and sawdust ash has been found to be rich in significant minerals such as $\mathrm{SiO} 2, \mathrm{Al} 2 \mathrm{O} 3$, $\mathrm{CaO}$ and Fe2O3 among others [26]. A number of studies have investigated into the use of sawdust as a pore forming agent in the production of porous ceramic materials used in building applications [25, 27, 28, 29, 30]. This is due to the fact that sawdust is waste material that can be cheaply sourced and at the same time contains valuable minerals. However, in most of these cases, sawdust has been used together with clayey materials. Research works on the effect of sawdust as a pore-forming agent on granite shifting are still scarce. Therefore, this research aims to explore into what other research efforts have done very little about and to provide a waste utilization strategy as well as promote cost-effective strategy for energy-efficient buildings.

The remaining parts of this study are arranged in the following order: Section 2 covers review of relevant literatures. Section 3 presents the materials and methods used in achieving the objectives of the study. Section 4 presents the results and discussion based on the findings in the study. Section 5, being the last section presents the conclusion derived from the outcome of the study.

\section{Literature Review}

\subsection{Achieving thermal comfort in buildings}


Since thermal comfort in buildings is required for healthy living of the occupants, according to [31], thermal comfort in building can be provided by either of two means, that is, active cooling designs or passive cooling designs. Active cooling designs refer to the use of mechanical and electrical driven devices such as fans, heaters and air conditioning systems to achieve thermal comfort in buildings. It can also be referred to as artificial means of cooling buildings. According to [31], the prevalent and abusive use of active driven mechanical devices has not only constituted series of environmental problems as a result of severe energy consumption and carbon emissions but has also led to energy crisis as a result of low generation, high cost and epileptic supply. On the other hand, passive cooling designs refer to design features or technology used in heating or cooling buildings naturally without energy consumption; it takes full advantage of the micro climate by using climate responsive design parameters. Providing insulation through building exterior envelope has been identified by [1] as one of the passive cooling techniques that can be adopted in design concept in buildings. In this regards, porous ceramics is an important material that can be used to achieve passive cooling of buildings. Among other available alternatives, using porous materials for improving the energy efficiency in buildings has received significant attention [32].

\subsection{Porous ceramics}

Porous ceramics have found applications in sound insulation, thermal insulation and also as lightweight aggregates concrete used in building and construction [10]. Porous ceramics represent a very interesting class of materials due to high surface area and permeability, low density and specific heat capacity, good moisture absorption, high thermal and acoustic insulation and high chemical resistance in addition to the fact that they are non-flammable and flame resistant, chemically inert and not toxic unlike polymeric foams [33, 34]. Due to the low apparent density and thermal conductivity, as well as acceptable compressive strength, porous ceramics can be used as a thermal and sound insulator, floors and wall tiles, architectural panels, filters, absorbers, gas sensors or, in the case of higher mechanical strength products, as aggregate of lightweight concretes, in road construction, infrastructures foundations, and sports grounds [35]. Since heat transfer in buildings can be through conduction, convection or radiation, thermal insulators such as porous ceramics help to prevent or reduce various forms of heat transfer with a similar principle to that of thermos flask, which can keep drinks hot or cold by providing an insulating layer between the liquid and the outside air. Given that air is a poor conductor of heat, it is the tiny pockets of air trapped within the insulating material which minimize the amount of heat that can pass between the inside and outside of a house. Therefore, porous ceramics is an important thermal insulation material.

\subsection{Different production techniques of porous ceramics}

Different techniques of fabricating porous ceramics include gel casting, replication of a sacrificial foam template, direct foaming of liquid slurry and foaming by sintering among others [36, 37]. Among all these techniques foaming by sintering has been widely used. This is traceable to the fact it is a production technique that offers easy usability with optimum results. Porous ceramics can be synthesized using two-step or one-step sintering technology. One-step powder sintering of porous ceramics is more economical given that it helps to reduce the cost of production [36] as well as reduce energy input required for the production of porous ceramics [37]. One-step sintering entails the use of chemical reagents to facilitate the production process of porous ceramics at a lower temperature by combining the procedures involved in two steps sintering into one. Therefore, one-step sintering method of porous ceramics production was used in this study due to its low cost of processing and eases for mass production.

\section{Materials and Method}

The materials that were used in this study include granite shifting, ball clay, saw dust, sodium hydroxide $(\mathrm{NaOH})$ and water glass (Na2SiO3). Granite shifting served as the main raw material. Ball clay served as the binder. Saw dust served as the pore-forming agent. Sodium hydroxide and water glass served as the sintering aid. The choice of granite shifting and saw dust in this study was necessitated by the increasing need for environmental sustainability through waste valorization as well as the abundance availability of these waste materials in Nigeria. While a number of previous studies in the area of porous ceramics have used either of $\mathrm{NaOH}$ or $(\mathrm{Na} 2 \mathrm{SiO} 3)$ as the sintering aid, this research makes an attempt to combine both chemicals for use as sintering aid in order to experiment what outcome this will give. Figures 1a-d show the raw materials that are used in this study. 


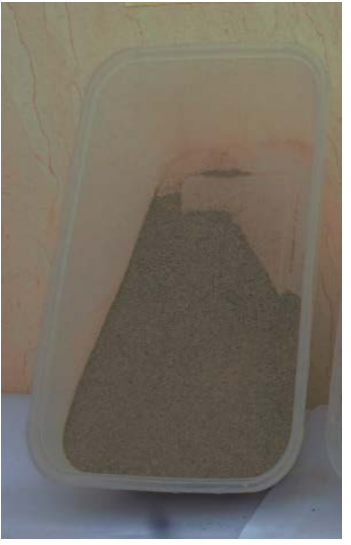

(a)

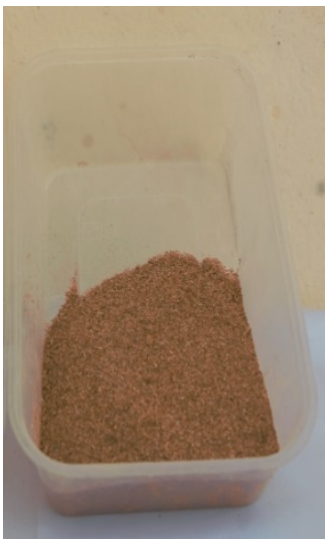

(b)

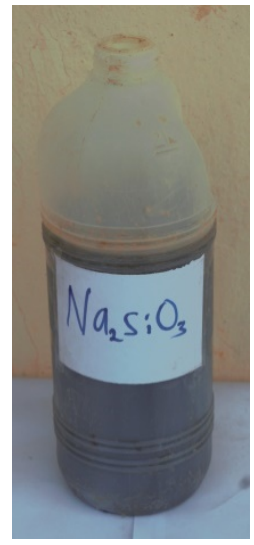

(c)

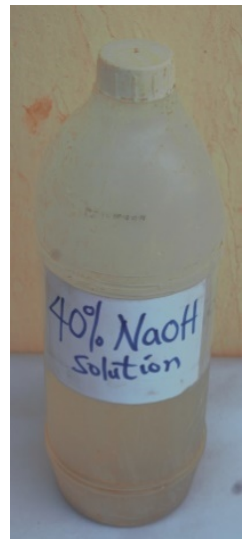

(d)

Fig. 1. (a) Granite shifting (b) Sawdust $\quad$ (c) Water Glass (d) $40 \%$ Sodium Hydroxide solution

\subsection{XRF Characterization of the Raw Materials}

Samples of the raw materials used in this study were analyzed using X-ray Fluorescence Spectrometer at the Nanotechnology Laboratory, Engineering Materials Development Institute (EMDI), Akure. The device used is SKYRAY INSTRUMENT, Model: EDX3600B. The EDX3600B X-ray fluorescence spectrometer applies XRF technology to conduct fast and accurate analysis of complex composition. The system detects elements between Magnesium (Mg, $\mathrm{Z}=12$ ) and Uranium (U, Z =92) with high resolution and fast analysis. The chemical composition of the raw materials used in this study is as shown in Table 1.

Table 1. Chemical Composition of the Raw Materials used in this study.

\begin{tabular}{llll}
\hline Oxide & Granite shifting & Ball Clay & Saw dust \\
\hline $\mathrm{Al}_{2} \mathrm{O}_{3}$ & 12.82 & 21.60 & 6.43 \\
$\mathrm{SiO}_{2}$ & 59.72 & 58.15 & 9.01 \\
$\mathrm{P}_{2} \mathrm{O}_{5}$ & 0.44 & 0.21 & 1.14 \\
$\mathrm{SO}_{3}$ & 0.82 & 0.71 & 5.06 \\
$\mathrm{~K}_{2} \mathrm{O}$ & 5.74 & 2.30 & 6.37 \\
$\mathrm{CaO}$ & 5.67 & 0.15 & 54.79 \\
$\mathrm{TiO}_{2}$ & 0.35 & 1.81 & - \\
$\mathrm{V}_{2} \mathrm{O}_{5}$ & 0.04 & 0.02 & 0.01 \\
$\mathrm{Cr}_{2} \mathrm{O}_{3}$ & - & 0.01 & - \\
$\mathrm{MnO}_{\mathrm{CoO}}$ & 0.07 & 0.03 & 0.03 \\
$\mathrm{Fe}_{2} \mathrm{O}_{3}$ & 0.23 & 0.35 & 0.06 \\
$\mathrm{NiO}$ & 11.29 & 14.40 & 10.15 \\
$\mathrm{CuO}_{\mathrm{ZnO}}$ & 0.04 & 0.05 & 0.09 \\
$\mathrm{WO}_{3}$ & 0.04 & 0.04 & 2.25 \\
$\mathrm{Au}_{2} \mathrm{O}$ & 0.09 & 0.09 & 0.20 \\
$\mathrm{Rb}_{2} \mathrm{O}$ & 0.12 & 0.05 & 0.16 \\
$\mathrm{Nb}_{2} \mathrm{O}_{5}$ & - & 0.05 & 0.12 \\
$\mathrm{MoO}_{3}$ & 0.07 & 0.01 & 0.01 \\
$\mathrm{SnO}_{2}$ & - & - & 0.06 \\
$\mathrm{Sb}_{2} \mathrm{O}_{3}$ & 0.25 & - & 0.54 \\
\hline
\end{tabular}

From Table 1, it can be observed that the main constituents of granite shifting are silicon oxide (SiO2), aluminium oxide (Al2O3) and iron oxide (Fe2O3) which represent 59.72\%, 12.82\% and $11.29 \%$ of the sample respectively. Other significant oxides that occur in the analyzed sample of granite shifting include potassium oxide (K2O) and calcium oxide (CaO) which represent $5.74 \%$ and $5.67 \%$ of the sample respectively. Major oxides contained in the ball clay are silicon oxide (SiO2), aluminium oxide (Al2O3) and iron oxide (Fe2O3) which represent 58.15\%, 21.60\% and $14.40 \%$ of the sample respectively. Other oxides that are present in significant amount include potassium oxide (K2O) and titanium oxide 
(TiO2) which represent $2.30 \%$ and $1.81 \%$ of the sample respectively. The major constituent of the sawdust sample analyzed and used in this study is calcium oxide (CaO) which represents $54.79 \%$. Other major oxides present in the sawdust sample include iron oxide (Fe2O3), silicon oxide ( $\mathrm{SiO} 2)$, aluminum oxide (Al2O3), potassium oxide (K2O), sulphur oxide (SO3), Copper oxide (CuO), tin oxide ( $\mathrm{SnO} 2)$, antimony oxide (Sb2O3) and phosphorus oxide (P2O5) which represent 10.15\%, 9.01\%, 6.43\%, 6.37\%, 5.06\%, 2.25\%, 1.84\%, 1.69\% and 1.14\% respectively.

\subsection{Raw Materials Preparation and Samples Formulation}

Granite shifting, ball clay and sawdust were separately sun dried and grinded using the grinding machine. Each of these was then sieved. Granite shifting and ball clay were sieved through $300 \mu \mathrm{m}$ British Standard /sieve while sawdust was sieved through $425 \mu \mathrm{m}$. In order to enhance the compaction of granite shifting, being a non-plastic material, ball clay was added in varying percentage by weight starting from $5 \%$ up to $50 \%$. It was found that addition of $50 \%$ clay to granite shifting aided its binding considerably. The mixture of 50\% clay and 100\% granite shifting was designated as GrC. $100 \mathrm{~g}$ of GrC was used for each of the samples under this test. $40 \% \mathrm{NaOH}$ solution was prepared by diluting $400 \mathrm{ml}$ of $\mathrm{NaOH}$ pellet in $1000 \mathrm{ml}$ of water. Samples formulation involved the use of varying percentage by weight of GrC and sawdust mixed with constant percentage by weight, sodium silicate $(\mathrm{Na} 2 \mathrm{SiO} 3)$ and sodium hydroxide $(\mathrm{NaOH})$ as shown in Table 2 which was achieved by making some adjustments to the batch composition of [14]. The formulated samples were thoroughly mixed. Each of the homogenized composition was poured into the mould with dimension $50 \mathrm{~mm} \times 50 \mathrm{~mm} \times 50 \mathrm{~mm}$ and uniaxially pressed at $10 \mathrm{MPa}$.

Table 2. Formulation of Porous Ceramic Samples

\begin{tabular}{|c|c|c|}
\hline $\begin{array}{l}\text { Samples } \\
\text { Grouping }\end{array}$ & $\begin{array}{l}\text { Sample } \\
\text { Formulation }\end{array}$ & Sample Code \\
\hline \multirow[t]{3}{*}{1} & $95 \% \mathrm{GrC}+5 \%$ Sawdust $+7.5 \% \mathrm{Na}_{2} \mathrm{SiO}_{3}+7.5 \% \mathrm{NaOH}$ & $\mathrm{S}_{1}$ \\
\hline & $90 \% \mathrm{GrC}+10 \%$ Sawdust $+7.5 \% \mathrm{Na}_{2} \mathrm{SiO}_{3}+7.5 \% \mathrm{NaOH}$ & $\mathrm{S}_{2}$ \\
\hline & $85 \% \mathrm{GrC}+15 \%$ Sawdust $+7.5 \% \mathrm{Na}_{2} \mathrm{SiO}_{3}+7.5 \% \mathrm{NaOH}$ & $\mathrm{S}_{3}$ \\
\hline \multirow[t]{3}{*}{2} & $95 \% \mathrm{GrC}+5 \%$ Sawdust $+10 \% \mathrm{Na}_{2} \mathrm{SiO}_{3}+10 \% \mathrm{NaOH}$ & $\mathrm{W}_{1}$ \\
\hline & $90 \% \mathrm{GrC}+10 \%$ Sawdust $+10 \% \mathrm{Na}_{2} \mathrm{SiO}_{3}+10 \% \mathrm{NaOH}$ & $\mathrm{W}_{2}$ \\
\hline & $85 \% \mathrm{GrC}+15 \%$ Sawdust $+10 \% \mathrm{Na}_{2} \mathrm{SiO}_{3}+10 \% \mathrm{NaOH}$ & $\mathrm{W}_{3}$ \\
\hline \multirow[t]{3}{*}{3} & $95 \% \mathrm{GrC}+5 \%$ Sawdust $+12.5 \% \mathrm{Na}_{2} \mathrm{SiO}_{3}+12.5 \% \mathrm{NaOH}$ & $\underline{S}_{1}$ \\
\hline & $90 \% \mathrm{GrC}+10 \%$ Sawdust $+12.5 \% \mathrm{Na}_{2} \mathrm{SiO}_{3}+12.5 \% \mathrm{NaOH}$ & $\underline{\mathrm{S}}_{2}$ \\
\hline & $85 \% \mathrm{GrC}+15 \%$ Sawdust $+12.5 \% \mathrm{Na}_{2} \mathrm{SiO}_{3}+12.5 \% \mathrm{NaOH}$ & $\underline{S}_{3}$ \\
\hline
\end{tabular}

\subsection{Drying and Sintering of the Formulated Samples}

The samples were dried in the electric oven at 1100C for 6 hours and then sintered in the gas kiln up to 8500C for 3 hours. Following the sintering of the samples which are made up of the addition of varying amounts of $\mathrm{NaOH}+\mathrm{Na} 2 \mathrm{SiO} 3$ (that is, $7.5 \%, 10 \%$ and $12.5 \%$ of each of the two chemical reagents) to granite shifting (95\%, 90\% and 85\%) together with sawdust $(5 \%, 10 \%$ and $15 \%)$ respectively at constant temperature of $8500 \mathrm{C}$,varying properties were observed in the resulting samples.

\subsection{Property Tests on the porous ceramic samples}

Property tests were carried out on the produced samples of porous ceramics to obtain their values of water absorption, bulk density, apparent porosity, compressive strength and thermal conductivity. Water absorption, bulk density and apparent porosity measurements were carried out on the sintered samples according to [38].

\section{(i) Water Absorption}

The water absorption test was conducted on the produced samples of porous ceramics by boiling the fired test pieces in water at $100^{\circ} \mathrm{C}$ for 2 hours, followed by an additional soaking in water for 4 hours. Water absorption was calculated using the equation:

$$
\mathrm{Wa}=\mathrm{Ws}-\mathrm{Wd} / \mathrm{Wd} \times 100
$$

where, $\mathrm{Wa}=$ Percentage absorption of water by the sample; $\mathrm{Ws}=$ soaked weight of the sample after boiling at $100^{\circ} \mathrm{C}$ for 2 hours; and $\mathrm{Wd}=$ dry weight of the sample. 
(ii) Bulk Density and Apparent Porosity

The dried weight of the sintered sample was taken. The sample was then soaked in boiling water for 3 hours and the soaked weight of the sample was taken. The sample was suspended in water using spring balance and the suspended weight of the sample was taken.

The bulk density was calculated following formula:

$$
\rho b=W_{1} \times \rho \mathrm{w} / \mathrm{W}_{2}-\mathrm{W}_{3}
$$

The apparent porosity was calculated using the formula:

$$
\mathrm{A}=\mathrm{W}_{2}-\mathrm{W}_{1} / \mathrm{W}_{2}-\mathrm{W}_{3}
$$

where $A=$ apparent porosity, $\rho b=$ Bulk density, $W_{1}=$ sintered weight of sample, $\rho \mathrm{w}=$ density of water $(\mathrm{g} / \mathrm{cm} 3), \mathrm{W}_{2}$ $=$ Soaked weight of sample in water, $\mathrm{W}_{3}=$ Suspended weight of samples in water

(iii) Compressive Strength

Compressive strength test was carried out on the produced samples with the aid of compressive strength testing machine, INSTRON SERIES 3369 at a fixed crosshead speed of $10 \mathrm{~mm} \mathrm{min-1} \mathrm{in} \mathrm{accordance} \mathrm{to} \mathrm{[39],} \mathrm{based} \mathrm{on} \mathrm{the} \mathrm{conventional}$ equation:

Compressive strength $=$ Maximum load $/$ Cross-sectional area

(iv) Thermal Conductivity

The area (A) and thickness $(\delta)$ of each of the samples was recorded. Each sample was fixed between two copper discs provided within the equipment set up. A conical flask containing $50 \mathrm{ml}$ of water was placed directly above and in contact with the sample. A thermometer passed through the cork of the conical flask to read the initial temperature (T1) of the water in the flask. The test section was then closed and the initial temperature of water in the conical flask was noted. A second thermometer was inserted into the steam outlet pipe offset to monitor the steam temperature so as to ensure a constant base temperature of $100^{\circ} \mathrm{C}(\mathrm{Ts}) .5$ litres of water was measured and poured into the boiler and it was ensured that the steam inlet valve, outlet valve, and condensate outlet valve were all closed. With the boiler cover remaining opened, the boiler was switched on. The boiler cover was closed immediately the water started boiling and the steam inlet valve was fully opened while all the remaining valves were closed. Immediately the steam inlet valve was opened, time reading $(\tau)$ commenced with the aid of a stopwatch. The experiment was timed in each case for 10 minutes (600 seconds) and the final temperature (T2) of the water in the conical flask was noted at the end of the fixed time. At the end of each experiment, the steam outlet valve was opened to release steam. The remaining samples were also subjected to the same experimental procedure as described above and the water in the boiler was refilled to maintain 5 litres in each case. The experiment was repeated twice for each of the test samples of cellular ceramics and a mean temperature value was obtained. The value of the thermal conductivity, $\mathrm{k}$ for each of the samples was determined using the formula [40, 41]:

$$
\mathrm{k}=2.303 \mathrm{MC} \delta\left[\log \theta_{1} / \theta_{2}\right] / \mathrm{A} . \tau
$$

where, $\mathrm{k}=$ the thermal conductivity of the specimen, $\left(\mathrm{W} / \mathrm{m}^{\circ} \mathrm{C}\right), \mathrm{M}=$ the mass of water in conical flask $(\mathrm{kg}), \mathrm{C}=$ specific heat capacity of water in conical flask $\left(\mathrm{J} / \mathrm{kg}^{\circ} \mathrm{C}\right), \delta=$ thickness of specimen $(\mathrm{m}), \theta_{1}=\mathrm{Ts}-\mathrm{T}_{1}$ and $\theta_{2}=\mathrm{Ts}-\mathrm{T}_{2}$, $\mathrm{Ts}=$ temperature of steam $\left({ }^{\circ} \mathrm{C}\right), \mathrm{T}_{1}=$ initial temperature of water in conical flask $\left({ }^{\circ} \mathrm{C}\right), \mathrm{T}_{2}=$ Final temperature of water in conical flask $\left.\left({ }^{\circ} \mathrm{C}\right)\right] \mathrm{A}=$ Specimen area $(\mathrm{m} 2)$ and $\tau=$ Time $(\mathrm{s})$.

\section{Results and Discussion}

\subsection{XRF result of the pore-forming agent (sawdust)}

From Table 1, it can be observed that the analyzed sample of the sawdust was found to contain metallic oxides. While sawdust is meant to serve as the pore-forming agent in this study due to the fact that it burn offs in the course of heat treatment leaving pores in the resulting material, it is obvious that the ash it leaves behind is inorganic in nature and therefore contains metallic oxides. Therefore, it could be inferred that the oxides contained in the sawdust ash have the tendency to react favourably with the oxides contained in the main raw material, that is, granite shifting mixed with ball clay. 


\subsection{Sintering result of the porous ceramic samples}

The sintering results of porous ceramics sample groupings fired in a gas kiln at $850^{\circ} \mathrm{C}$ for 3 hours are as shown in Figures 2-4. Group 1 samples contain $\operatorname{GrC}(95 \%, 90 \%$ and $85 \%)+$ sawdust $(5 \%, 10 \%$ and $15 \%)+7.5 \%$ $\mathrm{Na}_{2} \mathrm{SiO}_{3}+7.5 \% \mathrm{NaOH}$ respectively. Group 2 samples contain $\mathrm{GrC}(95 \%, 90 \%$ and $85 \%)+$ sawdust (5\%, $10 \%$ and $\left.15 \%\right)$ $+10 \% \mathrm{Na}_{2} \mathrm{SiO}_{3}+10 \% \mathrm{NaOH}$ respectively. Group 3 samples contain $\mathrm{GrC}(95 \%, 90 \%$ and $85 \%)+$ sawdust $(5 \%, 10 \%$ and $15 \%)+12.5 \% \mathrm{Na}_{2} \mathrm{SiO}_{3}+12.5 \% \mathrm{NaOH}$ respectively. The properties of the porous ceramic materials were observed to have been influenced by the amount of sawdust (pore-forming agent) and the chemical reagents $\left(\mathrm{NaOH}\right.$ and $\left.\mathrm{Na}_{2} \mathrm{SiO}_{3}\right)$ that served as the sintering aid. The sintering result as can be observed in Figures 2-4, showed that the more the amount of the sintering aid added to each of the samples in Groups 1-3, the better the samples sintered. It was also observed that the more the addition of sawdust to the samples the lighter in weight they become. Therefore, sample S3 in group 1 is the lightest weight while sample S1 is the heaviest among all the 9 samples.

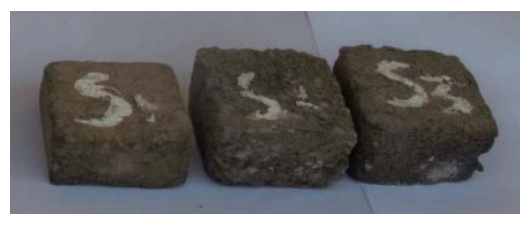

Fig.2. Sintered Porous Ceramic Samples (Group 1)

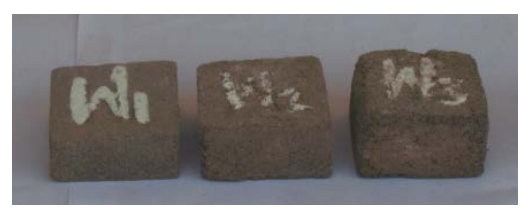

Fig.3. Sintered Porous Ceramic Samples (Group 2)

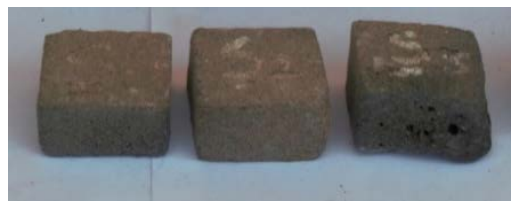

Fig.4. Sintered Porous Ceramic Samples (Group3)

\subsection{Trends in the properties of the porous ceramic samples}

Figures 5-9 show the effect of the addition of increasing amount of the pore-forming agent (sawdust) to constant amount of $\mathrm{Na}_{2} \mathrm{SiO}_{3}+\mathrm{NaOH}$ (in three different groupings that is, $7.5 \%, 10 \%$ and $12.5 \%$ of each the two reagents in each case) on the properties of the resulting porous ceramic samples sintered at $850^{\circ} \mathrm{C}$. From Figures 5 and 6 , it can be observed that there is an increasing trend in the values of water absorption, corresponding with increasing values of apparent porosity in each of the samples. Samples $S_{1}, S_{2}$ and $S_{3}$ consisting of $5 \%, 10 \%$ and $15 \%$ sawdust respectively with constant addition of $7.5 \% \mathrm{Na}_{2} \mathrm{SiO}_{3}+7.5 \% \mathrm{NaOH}$ have water absorption of $21.1 \%, 32.1 \%$ and $37.5 \%$ respectively; apparent porosity of $38.1 \%, 56.3 \%$ and $64.3 \%$ respectively. Samples $\mathrm{W}_{1}, \mathrm{~W}_{2}$ and $\mathrm{W}_{3}$ consisting of $5 \%, 10 \%$ and $15 \%$ sawdust respectively with constant addition of $10 \% \mathrm{Na}_{2} \mathrm{SiO}_{3}+10 \% \mathrm{NaOH}$ have water absorption of $21.7 \%, 31.4 \%$ and $52.2 \%$ respectively; apparent porosity of $40.0 \%, 55.0 \%$ and $80.0 \%$ respectively. Samples $\underline{\mathrm{S}}_{1}, \underline{\mathrm{S}}_{2}$ and $\underline{\mathrm{S}}_{3}$ consisting of $5 \%$, $10 \%$ and $15 \%$ sawdust respectively with constant addition of $12.5 \% \mathrm{Na}_{2} \mathrm{SiO}_{3}+12.5 \% \mathrm{NaOH}$ have water absorption of $35.0 \%, 38.2 \%$ and $56.5 \%$; apparent porosity of $60.0 \%, 63.6 \%$ and $81.3 \%$ respectively. Therefore, Sample $\mathrm{S}_{1}$ and Sample $\underline{S}_{3}$ have the lowest and highest value of water absorption of $21.1 \%$ and $56.5 \%$ as well as apparent porosity of $38.1 \%$ and $81.3 \%$ respectively. 


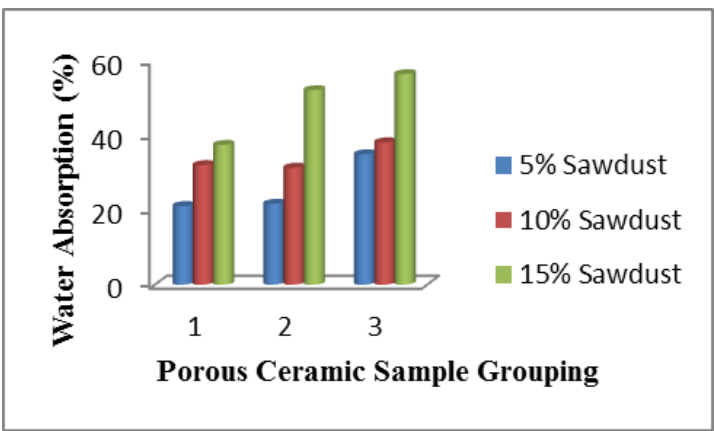

Fig.5. Water absorption of the porous ceramic samples

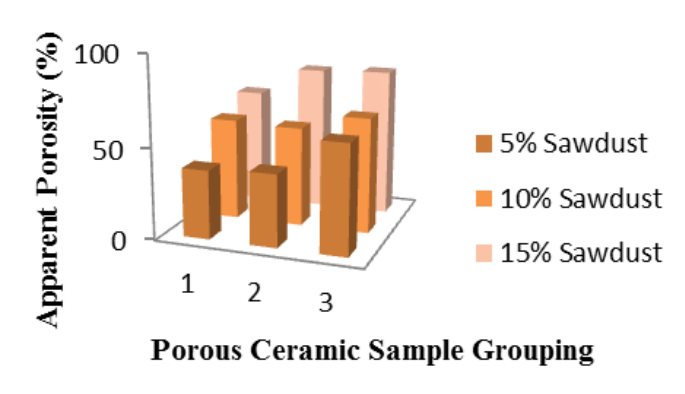

Fig.6. Apparent porosity of the porous ceramic samples

Figures 7 and 8 show decreasing values of bulk density corresponds with a linear decrease in the values of compressive strength of the samples with the increasing addition of the pore-forming agent in each case. Samples $\mathrm{S}_{1}$, $\mathrm{S}_{2}$ and $\mathrm{S}_{3}$ consisting of $5 \%, 10 \%$ and $15 \%$ sawdust respectively with constant addition of $7.5 \% \mathrm{Na}_{2} \mathrm{SiO}_{3}+7.5 \% \mathrm{NaOH}$ show bulk density of $1.81 \mathrm{~g} / \mathrm{cm}^{3}, 1.75 \mathrm{~g} / \mathrm{cm}^{3}$ and $1.71 \mathrm{~g} / \mathrm{cm}^{3}$ respectively; compressive strength values of $4.8 \mathrm{Mpa}, 2.5 \mathrm{Mpa}$ and 1.4Mpa respectively. Samples $\mathrm{W}_{1}, \mathrm{~W}_{2}$ and $\mathrm{W}_{3}$ consisting of $5 \%, 10 \%$ and $15 \%$ sawdust respectively with constant addition of $10 \% \mathrm{Na}_{2} \mathrm{SiO}_{3}+10 \% \mathrm{NaOH}$ have bulk density of $1.84 \mathrm{~g} / \mathrm{cm}^{3}, 1.75 \mathrm{~g} / \mathrm{cm}^{3}$ and $1.53 \mathrm{~g} / \mathrm{cm}^{3} \mathrm{respectively}$; compressive strength values of 7.9Mpa, 3.0Mpa and 1.2Mpa respectively. Samples $\underline{S}_{1}, \underline{S}_{2}$ and $\underline{S}_{3}$ consisting of $5 \%, 10 \%$ and $15 \%$ sawdust respectively with constant addition of $12.5 \% \mathrm{Na}_{2} \mathrm{SiO}_{3}+12.5 \% \mathrm{NaOH}$ have bulk density of $1.60 \mathrm{~g} / \mathrm{cm}^{3}$, $1.55 \mathrm{~g} / \mathrm{cm}^{3}$ and $1.44 \mathrm{~g} / \mathrm{cm}^{3}$ respectively; compressive strength values of 5.5Mpa, 3.3Mpa and 2.4Mpa respectively. Therefore, Sample $\mathrm{W}_{3}$ and Sample $\mathrm{W}_{1}$ have the lowest and highest value of compressive strength of $1.2 \mathrm{Mpa}$ and 7.9Mpa; while Sample $\underline{S}_{3}$ and $W_{1}$ have lowest and highest values of bulk density of $1.44 \mathrm{~g} / \mathrm{cm}^{3} \mathrm{and} 1.84 \mathrm{~g} / \mathrm{cm}^{3}$ respectively.

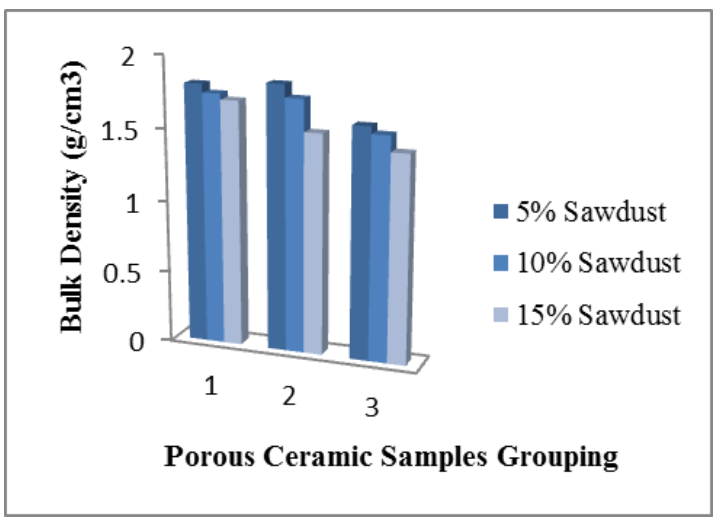

Fig.7. Bulk density of the porous ceramic samples 


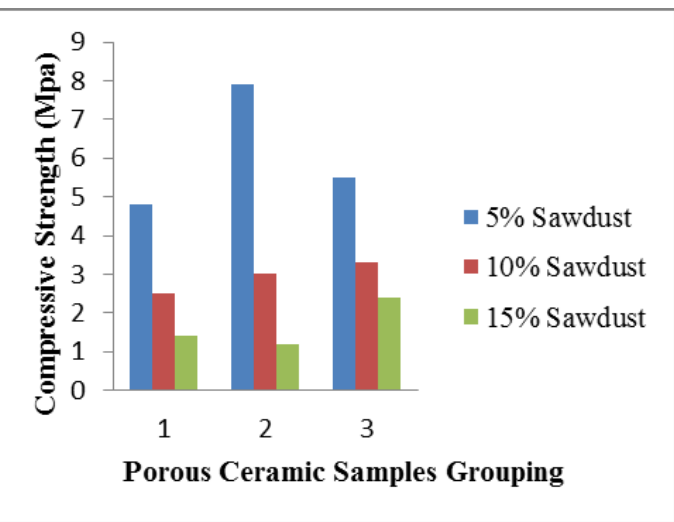

Fig.8. Compressive strength of the porous ceramic samples

As can be observed in Figure 9, the values of thermal conductivity of the samples decrease with the increasing addition of sawdust in each case. Samples S1, S2 and S3 have thermal conductivity values of $0.54 \mathrm{~W} / \mathrm{m} . \mathrm{K}, 0.43 \mathrm{~W} / \mathrm{m} . \mathrm{K}$ and $0.30 \mathrm{~W} / \mathrm{m} . \mathrm{K}$ respectively; Samples W1, W2 and W3 have thermal conductivity values of $0.35 \mathrm{~W} / \mathrm{m} . \mathrm{K}, 0.30 \mathrm{~W} / \mathrm{m} . \mathrm{K}$ and $0.23 \mathrm{~W} / \mathrm{m} . \mathrm{K}$ respectively; and Samples S1, S2 and S3 have thermal conductivity values of $0.26 \mathrm{~W} / \mathrm{m} . \mathrm{K}, 0.16 \mathrm{~W} / \mathrm{m} . \mathrm{K}$ and $0.13 \mathrm{~W} / \mathrm{m} . \mathrm{K}$ respectively. Therefore, Samples S3 and S1 have the lowest and highest thermal conductivity values of $0.13 \mathrm{~W} / \mathrm{m} . \mathrm{K}$ and $0.54 \mathrm{~W} / \mathrm{m} . \mathrm{K}$ respectively. The decreasing values of thermal conductivity correspond with increasing values of water absorption as well as increasing apparent porosity in each case.

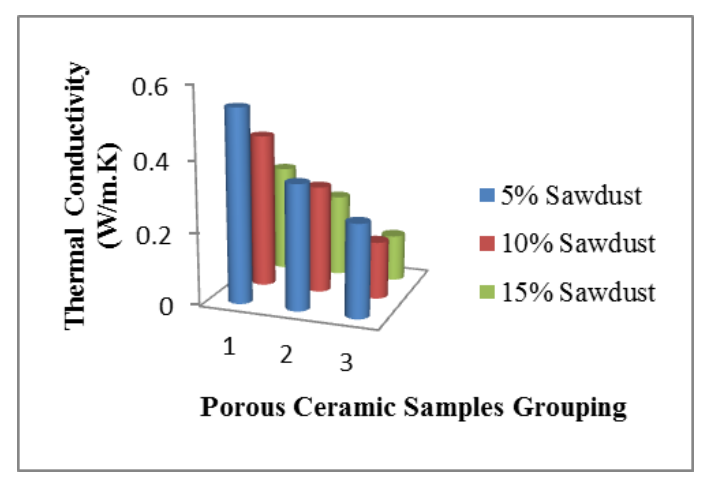

Fig.12. Thermal conductivity of the porous ceramic samples

In each of the three (3) porous ceramic sample groups, it can be observed that increasing the amount of sawdust used as the pore-forming agent (sawdust) and the increasing amount of chemical reagents (water glass and sodium hydroxide) used as the sintering aid influenced the properties of the produced samples. In general, there is an increasing water absorption and apparent porosity as well as decreasing thermal conductivity and decreasing bulk density, corresponding with a decreasing compressive strength in the porous ceramic samples in each case. This is in agreement with [42] that the more the amount of sawdust, the more the pores created in a thermal insulating material, thereby lowering the thermal conductivity values. Also, in agreement with [43] that higher amounts of the pore-forming agent generate higher amount of gas, as the amount of sawdust added to the samples increased, there was an observed decrease in the values of bulk density of the porous ceramic samples.

The thermo-mechanical properties of the porous ceramics prepared in this study compares favourably with the optimum sample of porous ceramics produced by [44] from coal fly and waste glass sintered at 8000C, having thermal conductivity and compressive strength of $0.36 \mathrm{~W} / \mathrm{m} . \mathrm{K}$ and $5.2 \mathrm{MPa}$ and $0.46 \mathrm{~g} / \mathrm{cm} 3$ respectively. When evaluated using EnergyPlus software, the result indicated that the optimum sample of the porous ceramics produced by [14] showed good energy conservation effect for building thermal insulation materials.

\section{Conclusion}

This study has provided documented procedure of fabricating porous ceramics for thermal insulation of buildings through chemical aided sintering of waste resources. It experimented into the one-step sintering fabrication method of porous ceramics from mining waste (granite shifting) and organic waste (sawdust) with the addition of suitable chemical reagents (water glass and sodium hydroxide). The results of the property tests conducted on the samples of the porous ceramics sintered at 8500C revealed water absorption (21.1-56.5\%), compressive strength (1.2-7.9Mpa), bulk density 
(1.44-1.81g/cm3), apparent porosity (38.1-81.3\%) and thermal conductivity $(0.13-0.54 \mathrm{~W} / \mathrm{m} . \mathrm{K})$. The results indicated that the porous ceramic samples developed in this study are characterized with moderate water absorption and apparent porosity, low thermal conductivity and high mechanical strength. Hence, based on the results of the properties tests, the porous ceramics obtained in this study is a potential material for cost-effective thermal insulation of buildings where suitable combination of thermal conductivity, porosity and mechanical strength are required. It is noteworthy that the effort made in this study towards the development of porous ceramics by one-step sintering technology through chemical activation is non-exhaustive. There are other possible areas for further research. Effect of other organic additives than the one used in this study, effect of varying concentrations of $\mathrm{NaOH}$, effect of varying sintering temperatures and effect of varying particles sizes on the porous ceramics produced should also be explored.

\section{References}

[1] Choudhary S., Thakur M.S. and Dogne N., Passive cooling techniques, design concept and ventilation techniques, Proceeding to National Conference on Alternative \& Innovation Construction Material Techniques TEQIP-II/Civil/AICMT-2, 2014; 5-11.

[2] Zhang, F. and Cooke, P., Green buildings and energy efficiency, Centre for Advanced Studies, Cardiff University, UK, 2010; 128. Available at: https://www.dime-eu.org/files/active/0/Cooke-2010-Fang-Green-building-review.pdf.

[3] Mardiana A, Riffat S.B., Building energy consumption and carbon dioxide emissions: threat to climate change. J Earth Sci Climat. Change, 2015, S3:001, 1-3, doi:10.4172/2157-7617.S3-001.

[4] Udodiong I., Here is how to survive the current severe heatwave in Nigeria, 2019. Available at: https://www.pulse.ng/bi/lifestyle/how- to-survive -the-current-severe-heatwave-in-nigeria/2r1c9de

[5] Sadiq L.,Why Jos has lowest temperature of 6.7 degree Celsius- NCRS, 2020. Available at: https://www.dailytrust.com.ng/whyjos-has-lowest-temperature-of-6-7-degree-celsius-ncrs.html

[6] Dalibi S.G., Feng J.C., Shuangqin L., Sadiq A., Bello B.S. \& Danja I.I., Hindrances to green building developments in Nigeria’s built environment: the project professionals’ perspectives, IOP Conf. Ser.: Earth Environ. Sci., 2017; 63:1-8, doi:10.1088/17551315/63/1/012033.

[7] Odewole P.O., Kashim I.B. and Akinbogun T.L., Towards energy-efficient building design in Nigeria: the possibilities of developing cost-effective wall insulation materials using indigenous ceramic technology, in 1st Visual Communication Design Conference, Federal University of Technology, Akure, Nigeria, 2019; 267-283.

[8] United Nations Industrial Development Organization (UNIDO), Thermal insulation properties and application in houses: technical manual, Vienna International Centre, Vienna, Austria, 2017. Available at: https://www.unido.org/sites/default/files/2017-09/House_Insulation_v_5.8_EN_0.pdf

[9] Taurino R., Lancellotti I., Barbieri L., and Leonelli C., Glass-ceramic foam from borosilicate glass, International Journal of Applied Glass Science, 2014; 1-10, DOI:10.1111/ijag.12069.

[10] Chinnam R. K., Bernardo E., Will J. and Boccaccini A. R., Processing of porous glass ceramics from highly crystallisable industrial wastes, Advances in Applied Ceramics, 2015; 114: sup1, S11-S16, doi: 10.1179/1743676115Y.0000000053.

[11] Chinnam, R.K., Functional glasses and glass-ceramics derived from industrial waste, doctoral dissertation, Department of Material Science and Engineering, Friedrich-Alexander-Universität Erlangen-Nürnberg, Germany, 2014. Available at: opus4.kobv.de>files> PhD_Thesis_Chinnam_WW7.

[12] Zhu M., Ji R., Li Z., Wang H., Liu L. and Zhang Z., Preparation of glass-ceramic foams for thermal insulation applications from coal fly ash and waste glass, Construction and Building Materials, 2016; 112: 398-405, doi: http://dx.doi.org/10.1016/j.conbuildmat.2016.02.183.

[13] Ivanov K.S., Preparation and properties of foam glass-ceramic from diatomite, Journal of Wuhan University of TechnologyMater. Sci. Ed., 2018; 273-277. DOI: https: //doi. org/10.1007/s11595-018-1817-8

[14] Kazmina O., Volkova A., Vereschagin V. and Rymanova I., Single-stage technology for granulated foam glass production based on the composition of tripoli and technological microsilica, IOP Conf. Ser.: Earth Environ. Sci., 2016; 43: 1-4, doi:10.1088/1755-1315/43/1/012067.

[15] Saakyan E., Arzumanyan A. and Galstyan G., Chemical technology of cellular glass production, E3S Web of Conferences, 2019; 97 (02012): 1-6, doi: https://doi.org/10.1051/e3sconf/20199702012.

[16] Lameed G.A. and Ayodele A.E. (2010) Effect of quarrying activity on biodiversity: case study of Ogbere site, Ogun State Nigeria, African Journal of Environmental Science and Technology, 4 (11): 740-750. ISSN 1991-637X.

[17] Ayodele O.J., Shittu O.S., Balogun T., Heavy metal pollution assessment of granite quarrying operations at Ikole-Ekiti, Nigeria, International Journal of Environmental Monitoring and Analysis, 2014; 2 (6): 333-339, doi: 10.11648/j.ijema.20140206.16.

[18] Eshiwani F., Effects of quarrying activities on the environment in Nairobi county: a case study of Embakasi District, Master Thesis, Department of Geography and Environmental Studies, University of Nairobi, Kenya, 2014. Available at: https://pdfs.semanticscholar.org/fb69/4269047997e656bd90ebd1d92f8d846fadf6.pdf

[19] de Lima-Filho V.X., Blazdell P.F., Nogueira R.E.F.Q. and Braga R., Studies on sintering of molded granite bodies, Congresso Brasileiro De Engenharia Ciência Dos Materiais, 2000; 14: 10401- 10411.

[20] Dhanapandiana S. and Shanthib M., Utilization of marble and granite wastes in brick products, Journal of Industrial Pollution Control, 2009; 25 (2): 145-150.

[21] Bayraka G. and Yilmazb S., Granite based glass-ceramic materials, Acta Physica Polonica A, 2014; 125 (2): 623-625, doi 10.12693/APhysPolA.125.623.

[22] Bobkova N.M., Barantseva S.E., and Trusova1 E.E., Production of foam glass with granite siftings from the Mikashevichi deposit, Glass and Ceramics, 2007; 64 (1-2): 47-50.

[23] da Silva L.L., Ribeiro L.C.N., Santacruz G., Arcaro S., Alves A.K. \& Bergmann C.P., Glass foams produced from glass and Yerba Mate (Ilex Paraguarinensis) waste, FME Transactions, 2018; $46 \quad$ (1) 70-79. 
[24] Mothé C.G. and Ambrósio M.C.R., Processes occurring during the sintering of porous ceramic materials by TG/DSC, Journal of Thermal Analysis and Calorimetry, 2007; 87 (3): 819-822.

[25] Chemani H. and Chemani B., Effect of adding sawdust on mechanical-physical properties of ceramic bricks to obtain lightweight building material, International Scholarly and Scientific Research \& Innovation, 2012; 6 (11): $2521-2525$.

[26] Butt W.A., Gupta K. \& Jha J.N., Strength behavior of clayey soil stabilized with saw dust ash, International Journal of GeoEngineering, 2016; 7 (18): 2-9, doi 10.1186/s40703-016-0032-9.

[27] Elinwa A.U., Effect of addition of sawdust ash to clay bricks, Civil Engineering and Environmental Systems, 2006 ; 23 (4): $263-$ 270, doi 10.1080/10286600600763149.

[28] Chemani H. and Chemani B., Valorization of wood sawdust in making porous clay brick, Academic Journals, 2013; 8 (15): $609-$ 614, doi 10.5897/SRE12.608.

[29] Phonphuak N. et al, The use of sawdust waste on physical properties and thermal conductivity of fired clay brick production, International Journal of GEOMATE, 2020, 18 (69): 24-29, https://doi.org/10.21660/2020.69.5706

[30] Cultrone G., Aurrekoetxea I., Casado C. \& Arizzi A. Sawdust recycling in the production of lightweight bricks: How the amount of additive and the firing temperature influence the physical properties of the bricks, Construction and Building Materials, 2020; 235, (117436): 1-13, DOI: https://doi.org/10.1016/j.conbuildmat.2019.117436

[31] Aramide F.O., Production and characterization of porous insulating fired bricks from Ifon clay with varied sawdust admixture, Journal of Minerals and Materials Characterization and Engineering, 2012; 11, 970-975, doi 10.4236/jmmce.2012.1110097.

[32] Adebisi I.I, Ayinla A.K. and Okeyinka Y.R. (2018) Energy Efficient Buildings in Tropical Climate through Passive TechniquesAn Overview, Journal of Environment and Earth Science, 8 (4): 45-50.

[33]. Rashidi A., Esfahani J.A. and Karimi N., Renewable and Sustainable Energy Reviews, 91 (2018) 229.

[34] Rincon A., Marangoni M., Cetin S. and Bernardo E., Recycling of inorganic waste in monolithic and cellular glass-based materials for structural and functional applications, J. Chem. Technol. Biotechnol., vol. 91, pp. 1946-1961, 2016, doi: https://doi.org/10.1002/jctb.4982.

[35] Khamidulina D.D., Nekrasova S.A., and Voronin K.M., "Foam glass production from waste glass by compression," IOP Conf. Ser. Mater. Sci. Eng., vol. 262, no. 1, 2017, doi: 10.1088/1757-899X/262/1/012008.

[36] Dragoescu M.F., Axinte S.M., Paunescu L. and Fiti A. (2018) Foam glass with low apparent density and thermal conductivity produced by microwave heating, European Journal of Engineering and Technology, 6 (2):1-9

[37] Yuan H., Wu H., and Guan J., "Synthesis of foam glass-ceramic from CRT panel glass using one-step powder sintering," IOP Conf. Ser. Earth Environ. Sci., vol. 186, no. 2, 2018, doi: 10.1088/1755-1315/186/2/012020.

[38] Cheng C., Feng K., Zhou Y., and Zhou H., "Effect of sintering temperature on the microstructure and properties of foamed glass-ceramics prepared from high-titanium blast furnace slag and waste glass," Int. J. Miner. Metall. Mater., vol. 24, no. 8, pp. 931-936, 2017, doi: 10.1007/s12613-017-1480-8.

[39] ASTM C20-00, "Standard test methods for apparent porosity, water absorption, apparent specific gravity, and bulk density of burned refractory brick and shapes by boiling water”, ASTM International, West Conshohocken, PA (2010).

[40] ASTM C240-97, "Standard test methods of testing cellular glass insulation block”, ASTM International, West Conshohocken, PA (1998).

[41] Obidiegwu E.O., Esezobor D.E., Agunsoye J.O. and Lawal G.I., Enhancement of insulating refractory properties of selected Nigeria fire-clays using coconut shell, Journal of Minerals and Materials Characterization and Engineering, 2015; 3: 458-468, http://dx.doi.org/10.4236/jmmce.2015.36048.

[42] Aramide, F.O. (2012), "Production and characterization of porous insulating fired bricks from Ifon clay with varied sawdust admixture”, Journal of Minerals and Materials Characterization and Engineering, Vol. 11, pp. 970-975.

[43] Folorunso D.O., Characterization and value enhancement of some Nigerian refractory materials for thermal insulation, IOSR Journ. of Mech. and Civil Eng. (IOSR-JMCE), 2018, 15 (3-3): 79-86, doi: 10.9790/1684-1503037986.

[44] da Silva R.C., Kubaski E.T., and Tebcherami S.M., Glass foams produced by glass waste, sodium hydroxide, and borax with several pore structures using factorial designs, Int. J. Appl. Ceram. Technol., 2019; 1-9, doi 10.1111/ijac.13210.

[45] Zhu, M., Ji, R., Li, Z., Wang, H., Liu, L. and Zhang, Z. (2016), "Preparation of glass-ceramic foams for thermal insulation applications from coal fly ash and waste glass”, Construction and Building Materials, Vol. 112, pp. 398-405.. 


\section{Authors' Profiles}

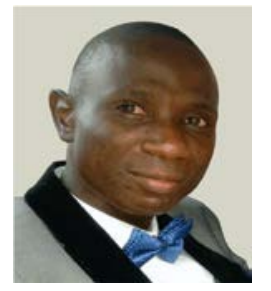

Odewole Peter Oluwagbenga holds a B.Sc. in Glass Technology from Ahmadu Bello Univeristy, Zaria and M.Tech in Industrial Design from the Federal University of Technology, Akure with specialization in ceramics. He is a budding researcher who strongly desires to advance research works that will promote knowledge towards the development of ceramic science and technology in Nigeria and Africa at large. He has presented research papers in conferences and published in both national and international peer reviewed journals. His current research interest is on production of porous ceramic materials for thermal insulation of buildings using local and waste resources.

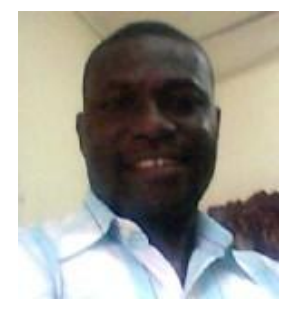

Folorunso Davies Oladayo is currently an Associate Professor at the Department of Metallurgical and Materials Engineering, Federal University of Technology, Akure. He is a registered member of Council for the Regulation of Engineering in Nigeria (COREN). His research team is currently working on the hydrometallurgical preparation of refined local clays for use in furnace lining bricks. He can be contacted at: dofolorunso@futa.edu.ng.

How to cite this paper: Odewole Peter Oluwagbenga, Folorunso Davies Oladayo, " Fabrication of a Porous Ceramic Material Suitable for Cost-effective Thermal Insulation of Buildings ", International Journal of Engineering and Manufacturing (IJEM), Vol.10, No.5, pp.45-56, 2020. DOI: 10.5815/ijem.2020.05.05 